\title{
Editorial: Felix Culpa
}

Many strange documents arrive on the desk of a philosophical editor. One that we hope will remain unique came as a covering letter to a review copy of a work on philosophical theology. In it the publisher's publicity manager commended the book as likely to be of interest to our readers, and went on to give us the author's suggestion that Professor Whatsisname of the University of Whereisit would be a suitable reviewer. One might expect a publicity manager to know, even if an author might not, that such a seed is likely to fall on stony ground. Only a small minority of books can be reviewed at all, and acts of provocation are counterproductive.

But if space is so short, how does it happen that in this issue there are two reviews of the same book? The candid answer to this fair question is that it has happened by oversight. We have so far escaped the editor's nightmares-the article that is printed twice and the article that is not printed at all because it is lost and the author has kept no copy-but a lesser bad dream has come true, the sending of the same book to two reviewers. The error was not noticed until it happened by uncovenanted coincidence that the two reviews reached the desk on the same afternoon. The mishap has turned out well. The two reviews of Donald Davidson's Inquiries into Truth and Interpretation that are printed on pp. 405-411 are mutually complementary, and each displays on its own account the virtues proper to a review: they are clear, informative, interesting and judicious. The only amendment needed by either was needed by both: the substitution of 'if and only if' for 'iff'. We have a statutory duty as well as an ingrained inclination to censor needless technicality.

Our felix culpa has several causes over and above editorial incuria. The publisher sent two copies of the book at different times. The earlier was despatched to Dr Heal at Newcastle, but did not reach her for several months, having been swallowed by the Departmental Library and disgorged only after anxious probing. By then the second copy had been offered to Dr Guttenplan. Another book of essays by Professor Davidson had appeared not long before, so it was possible for the left hand to think that the right hand was dispensing a different work to a different reviewer.

If a deliberate practice were made of sending books to more than one reviewer, Mr Magee's Schopenhauer would have been a good case for such treatment. It might have been sent not only to a philosopher who had the advantage of having written on the same subject, but also to one who had the advantage of not having written 


\section{Editorial}

on the same subject. We have taken the unusual step of printing a reply by $\mathrm{Mr}$ Magee to Professor Hamlyn's review as the nearest practicable approximation to providing such an amenity.

About Mr Magee's point of principle we remain undecided. The golden rule is that there are no golden rules. The only rule that comes near the gold standard is that the author of an unsolicited review is either the friend of the author or the enemy of the author, and should be treated as cautiously as one would treat a publicity manager. 